\title{
TÜRK MENŞELİ BAZI ÇİN AİLELERİ: HUN, LI, JIIN VE YUWEN
}

\section{Kürşat YILDIRIM*}

\begin{abstract}
ÖZ
Türk milletine mensup çok sayıda ailenin Çin içerisinde gidip Çinlileştikleri tarihî bir hakikattir. Türk aileleri Çinlileştikleri zaman ilk iş olarak Çince aile adları almışlardır. Bu aileler tarihî süreçte türlü adlarla anılmışlar ve türlü yerlerde görünmüşlerdir. Bugünkü Çin’de bazı Çinli ailelerin menşei, taşıdıkları adlar sayesinde tespit edilebilmektedir. Bu makalede Çin kaynaklarına dayanarak Çinlileşen Hun, Li, Jin ve Yuwen adlı ailelerin tarihî seyirlerini ve bugün yaşadıkları yerleri tespit etmeye çalışacağız.
\end{abstract}

Anahtar Kelimeler: Türk aileleri, Çin aileleri, Çin kaynakları, Çin, Çinlileşmek, tarih, etnoloji

\section{SOME CHINESE FAMILIES FROM TURKIC ORIGIN: HUN, LI, JIN AND YUWEN}

\begin{abstract}
It is a historical fact that many Turkic families went to China and became Chinese. After Turkic families became Chinese, they took a Chinese family name firstly. These families are referred to by any name and they appeared in different place in historical process. Today, origin of some Chinese families can be discovered by the names they carry. In this article, we will try to define Turkic families named Hun, $\mathrm{Li}$, Jin and Yuwen who became Chinese, to identify historical course of them and to determine where they live today based on Chinese sources.
\end{abstract}

Keywords: Turkic Families, Chinese Families, Chinese Sources, China, Become Chinese, History, Ethnology.

Aile veya soy adları binlerce yıldır yazısını devam ettiren Çin toplumunda belli bir kaideye tâbidir. Yerleşik toplum yapısı ve yazı geleneğinin sağlamlığı sayesinde tarihte aile adını kullanmaya başlayan ilk halkın Çinliler oldukları bilinmektedir. Aile adları eski Çin toplumunda kişilerin kimlikleridir; kapalı ve köleci ve/veya feodal toplum yapısı içinde sınıf ve statü gibi müesseselerde belirleyici değişken aile adıdır.

Tarih araştırmalarında müracaat edilebilecek kaynaklardan birisi, aile adlarıdır. Çin terkibine girmiş ve Çinlileşmiş toplulukların ve ailelerin erken tarihlerinin ortaya çıkarılması birçok bakımdan tarihçinin işini kolaylaştıracaktır. Her şeyden önce tarihin belli döneminden sonra Türk toplulukları arasında görülmeyen insanların bugüne kadarki seyirleri hakkında fikir sahibi olunabilir ve

\footnotetext{
* Yrd. Doç. Dr., İstanbul Üniversitesi, Edebiyat Fakültesi, Tarih Bölümü. Shanghai International Studies University (上海外国语大学) Şeref Üyesi, kursatyildirimtr@yahoo.com.
} 
Çinli olarak addedilen insanların veya Çin olarak bilinen toprakların asıl sekenesi veya bu sekene içerisinde Çinlileşenlerin terkibi tespit edilebilir. İkinci olarak bugün kendisini Çinli olarak tanımlayan insanların menşeleriyle ilgili meraklarını gidermeye yardımcı olabilecek bir katkı sağlanabilir. Üçüncü olarak etnik teşekkül saflarının araştırılmasına ailelerin adlarına ve yerleştikleri yerlere bakılabilir. Son olarak ise Türk milletinden kopup giden ve Türklügünü yitiren insanların bir çetelesi çıkarılabilir. Türklük Çin içerisinde diğer herhangi bir coğrafya ile kıyaslanamayacak kadar çok erimiştir. Tarih boyunca Çin içerisine gidip yerleşen Türkler, milliyetlerini kaybedip Çinlileşmişler ve Çin aile adları almışlardır. Bu adların tahlili neticesinde ailelerin Türk menşelerini açığa çıkarmak ilmî metotlarla mümkündür.

$\mathrm{Bu}$ konuyu ele alırken öncelikle eski Çin toplumunda ailelerin nasıl ad aldıklarına temas etmek lazımdır. Çin tarih yazımında ve edebiyatında aile veya soyadına karşılık olarak xing 姓 ve shi 氏 işaretleri kullanılmaktadır. Çin tarihçiliğindeki rivayete göre varlığı tartışmalı Sarı İmparator (İmparator Huang 黃 帝; M.Ö. 3000 yılları)'un 25 oğlu vardı ve bunlar 12 aileye bölünmüşlerdi, yani xing diye ifade edilen 12 aile adı ortaya çıkmıştı. Çin tarihinin chun-qiu denen döneminde (M.Ö. 771-476) aile adlarının sayısı artık 21 idi. Bu devirlerde aile adını ifade eden xing, ana tarafından gelen soyu işaret ediyordu; çünkü Çin toplum yapısı bu devirlerde anaerkil idi. Soyda kadın tarafı esas alınıyordu ${ }^{1}$. Takriben M.Ö. V. yüzyıldan itibaren ise babaerkillik ve buna bağlı olarak aile, sülale ve kabileler şekillenmiş ve böylece soyadını ifade eden işaret olarak esasen shi 氏 işareti kullanılmaya başlanmıştır $^{2}$. Bu aile adları yazılı vesikalarda muntazaman kaydedilmiş, aile adlarındaki değişiklikler ve bazen de göç edilen yerler belirtilmiştir. Böylece ailelerin aldıkları adların rastgele olmadığı ve belli bir silsileye dayandığı aşikârdır. Nitekim bugünkü Çin toplumunda dahi aynı aile adını taşıyanlar esasen akraba olduklarına inanmaktadırlar ${ }^{3}$.

Eski Çin toplumunda aile adı rastgele alınmamaktadır ve alınan adın mutlaka bir sebebi vardır. Bu münâsebetle Çin içerisine yerleşen ve Çinlileşen Türk ailelerinin adlarını tespit edip, adların ilk görünüşlerini ve seyirlerini ele alacağız:

\section{Hun 渾}

Xin Tang Shu 新 唐 書’ya göre Hunların Hunya 渾 邪 Beyi’nden gelme Hun 渾 Ailesi, Tuoba 拓 拔 Ailesi'ni takip ederek Henan 河南'a yani Sarı Irmak'ın güneyindeki topraklara göçmüştür. Bu aile, beyleri olan Hun Huigui'den Hun Jian (ölm. 799)'a kadar, yani VII. yüzyıldan IX. yüzyılın sonlarına kadar Çinliler tarafından kurulan Gaolan 畠 蘭 Eyaleti Valiliği’ni elde tutmuştur ${ }^{4}$.

XII. yüzyılda kaleme alınan Gujin Xingshi Shu Bianzheng 古今姓氏書辯 證 adlı kaynağa göre Hun 渾 Ailesi, Hunların Hunya 渾 邪 Beyi’nden gelmeydi. Bunlar Tuoba 拓 拢 Ailesi'ni takip ederek Henan'a göçmüşlerdi. Sui ve Tang devirleri arasında (VI. yüzyılın sonu-VII. yüzyılın başı), bu aile boy (Çince karşılığı:

\footnotetext{
${ }^{1}$ Wang Quangen, Zhongguo Xingshi de Wenhua Jiexi, Tuanjie Chubanshe Yay., Beijing, 2000, s. 35-36.

${ }^{2}$ Wang Quangen, a.g.e., 54-56.

${ }^{3}$ Chen Shaoxin-Furuide, Taiwan Renkou zhi Xingshi Fenbu, Taipei, 1970, s. ii.

${ }^{4}$ XTS, s. 3379.
} 
bu 部) hâline gelmiş, Uygurlara (Huige 回 鶻) bağlanmış ve Dokuz Oğuz (Çince karşılığı: Jiuxing 九 姓) boyları arasında yer almıştı. Boyun otağı en güneydeydi. Zhenguan saltanat devresinde (627-649), Xueyantuo 薛 延 陀 (Sir Tarduş)'lar Dokuz Oğuzların başındaki Ulu İlteber'i öldürünce Hun boyu Çin'e tâbi oldu ve Gök-Türkleri boyunduruk altına alan Çin, 648 yılında Hangai Dağları havalisini idâre etmek üzere kurduğu sözde Yanran 燕 然 Valiliği’ne bağlı olarak Hun ailesinin yayıldığı yerde, yani Tola Irmağı'nın kuzeyinde kalan topraklarda Gaolan 臭蘭 Valilik İdaresi kurdu. Hun boyunun beyi olan Atanzhi 阿圓支’ya Çince Tan 潭 adı ve “Sui İmparatorluğu’nun Yeşimtaşı Stratejisi Muhafızı (Yuqianwei 玉 鈐 衛) Büyük General”, “Tang İmparatorluğu'nun Pars Stratejisi Muhafızı (Baotaowei 豹粨 衛) Büyük General” gibi unvanlar verildi ${ }^{5}$.

Böylece Hun ailesinin (urug olarak da adlandırılabilir) Uygur ittifakı içinde, "Dokuz Oğuz"dan biri olarak yer aldığı ve Töleslerden gelme olduğu anlaşılmaktadır. Esasında Uygurların menşei ile ilgili tartışmalarda odak noktası Dokuz Oğuzlardır. Gök-Türk kaganlarının Dokuz Oğuzlardan çıktığına dair W. Barthold'un görüşü makul gibi görünmektedir. İbrahim Kafesoğlu'nun yaptı̆̆ tespitlere göre Çin kaynaklarında geçen "Dokuz Boy" veya "Dokuz Kabile" ifadesi bazen "Türklerin Dokuz Boyu”, "Dokuz Boyun Türkleri”, "Töleslerin Dokuz Boyu” şeklinde de görülmektedir ${ }^{6}$. Yine bazı araştırmacılar Hun ailesinden bahsederken “Uygur Hun” (Huige Hun 回 鶻渾) demektedirler" . O hâlde Hun ailesinin, adı "Türk" veya "Uygur" olan siyasi bünyenin kurucu ailesi olduğu neticesi ortaya çıkmaktadır. Hun ailesinin VII. yüzyıla dair kaynaklarda "boy" olarak zikredilmesinin sebebi de bu olmalıdır. Aile mensuplarının VII. yüzyılın ilk yarısında Xueyantuo (Sir Tarduş)'ların Dokuz Oğuzların başındaki Ulu İlteber'i öldürmesiyle Çin'e sığınmaları, Çin hizmetine girmeleri ve Çinlileşmeye başlamaları hadisesini doğru değerlendirmek gerekmektedir, çünkü Uygur Kaganlığ kurulurken Hun ailesi veya urugu Dokuz Oğuz mensubu olarak mevcuttu. Dolayısıyla yine bir Dokuz Oğuz mensubu olan Sir Tarduş'ların hareketi neticesinde ailenin sadece beyinin yakınlarıyla beraber Çin'e gittiği ve Çinlileştiği anlaşılmaktadır. Çin kaynaklarında adları tek tek zikredilen ve Çin'de yüksek mevkilere gelen beyin nesli bunu göstermektedir. Hun ailesinin yürüttüğü ve zhenguan saltanat devresinin 21. yılında (647) Tola Irmağı'nın kuzey kıyısında kurulan ${ }^{8}$ Gaolan Valiliği'nin idare merkezi yonghui saltanat devresinde (650-655) Gansu'ya, Hun ailesinin atası olan Hunya'nın bir Hun beyi olarak idare ettiği topraklara, bugünkü Ningxia'daki Wuzong Şehri havalisine kaydırılmıştır. Jiu Tang Shu'daki coğrafya kayıtları da bunu doğrulamaktadır ${ }^{9}$. Böylece ailenin Çinlileştiğinin bir başka emaresi ise idare ettiği valilik makamının Çin topraklarındaki Gansu'ya taşınması olmaktadır ${ }^{10}$.

\footnotetext{
${ }^{5}$ GBC, s. 107.

${ }^{6}$ İbrahim Kafesoğlu, Türk Millî Kültürü̈, İstanbul, 2003²3, s. 151-152.

${ }^{7} Y W K$, s. 90.

${ }^{8}$ Zhongguo Lishi Diming Da Cidian, Ed., Shi Weile, Beijing, 2005, s. 2143.

${ }^{9}$ JTS, s. 1415.

${ }^{10} \mathrm{Bu}$ valilik hakkında tafsilatlı bilgi için bkz. Maeda Masana, Hexi Lishi Dili Yanjiu, Çin. Çev., Chen Junmo, Zhongguo Zangxue Chubanshe Yay., Beijing, 1993, s. 34-39.
} 
$\mathrm{Bu}$ arada Töles boylarına dair Çin kaynaklarında ailenin VII. yüzyıl başlarında Tola Irmağı etrafında olduğu kaydı ile ${ }^{11}$ ailenin Tabgaçlarla birlikte Henan'a, yani Sarı Irmak'ın güneyine indikleri kaydı birbiriyle çelişmemektedir. Tabgaçların güneye inmeleri takriben II. yüzyılın ikinci yarısından sonraya denk düşmektedir ${ }^{12}$. Hunların bölünme ve göçme devirlerinde Hun beyinden gelme olan ailenin Tabgaçlarla birlikte güneye inmeleri, Çin'in ve Gansu bölgesinin irili ufaklı birçok gücün mücadelesine sahne olması sebebiyle tekrar kuzeye, asıl yurtlarına dönmüş olmaları gayet tabiidir.

630'larda Çin tâbi olan Atanzhi'nin evladı Hun Huigui "Sol Atak Muhafiz (Zuowuwei 左 武 衛) Büyük General”, "Ningshuo İlçesi Beyi"; onun evladi Hun Yuanqing “Devlet Muhafiz Büyük Generali” (Zhenguo Da Jiangjun 鎮 國大將軍); onun evladı Hun Dade "Sol Atak Muhafız Büyük General"; onun evladı Hun Chengzhi "Sol Orduya Emir Büyük Muhafız Generali" gibi makamlara yükseldiler" Yine Hun Jian (735-799), Tang İmparatorluğu'nda bakan seviyesine çıktı ${ }^{14}$. Yine bu aileden Hun Jian'ın torunu Hun Gao gibiler de Çin ordularında yüksek mevkilere geldiler $^{15}$. Hun Jian, Çin tarihinde bilhassa önemli bir figürdür; kendisi isyan eden Zhu Ci (ölm. 784)'ye karşı Tang İmparatoru De Zong'u kurtaran bir Çin generali olarak ün yapmıştır ${ }^{16}$.

Tong Zhi 通志'nin Shi Zu Lue 氏 族略 bölümünde ${ }^{17}$ ve Yuan He Xing Zuan 元和姓 纂' ${ }^{18}{ }^{18}$ kaydedildiğine göre Hun 渾 ailesi, Tuyuhun 吐谷渾'ların aile adından gelmedir ve değişip sadece Hun hâline dönüşmüştür. Böylece bir kısım Hun ailesi mensuplarının ise Tuyuhun'lardan gelme olduğu anlaşılmaktadır.

Bugün Sarı Uygurlarda da görülen Hun Ailesi'nin çoğu Çinlileşmiştir. Sarı Uygurlar arasındaki Hun Ailesi'ne "Kızıl" adı da verilmektedir. Çinlileşen Hun Ailesi mensupları bugün Shanxi'deki Jiang İlçesi'nde, Datong'da, Linfen'da, Yuncheng'da, Jincheng'da, Xia İlçesi'nde; Beijing'de; İç Moğolistan'nın merkezi Köke Qota'da; Hunan'daki Lingshuijiang'da; Hebei'deki Suning'de, Xian İlçesi'nde; Gansu'daki Jingtai'da; Shanghai'da ve Tianjin'de yaşamaktadırlar ${ }^{19}$.

\section{Li 利:}

Bugün tamamen Çinlileşen Li 利 Ailesi’nin adının en erken formlarından birisi Töles ailelerinden biri olarak zikredilen Qifuli 泣 伏利'dir. Ad kaynaklarda Chili 吨利 şeklinde de görülmektedir.

Wei Shu 魏 書'da Tabgaç Devleti'ne dâhil büyük aile ve sülâlelerin kaydedildiği Guan Shi Zhi 官氏 志 bölümüne göre Tabgaçların Ulu Atası Li Wei

\footnotetext{
${ }^{11}$ BS, s. 3303; Ahmet Taşağıl, Çin Kaynaklarına Göre Eski Türk Boyları, Ankara, 2004, s. 62.

${ }^{12}$ Kürşat Yıldırım, "Erken Tabgaç (T’o-Pa) Tarihinin Ana Hatları (Wei Shu'nun İlk Bölümüne Göre)", Turkish Studies, VII/3, 2012, s. 2714.

${ }^{13}$ XTS, s. 3380 .

${ }^{14} G B C$, s. 107.

${ }^{15}$ CWD, s. 183. Bu unvanların Türkçe karşılıkları için C. O. Hucker'in A Dictionary of Official Titles in Imperial China (California, 1985) adlı eserinden yardım alınmıştır.

${ }^{16} \mathrm{Hu}$ Jian'ın biyografisi için bkz. JTS, s. 3703-3710.

${ }^{17}$ TC, s. 456 b.

${ }^{18}$ YHHT, s. 473.

${ }^{19}$ YQD, s. 1277.
} 
(M.S. 220-277) devrinde Tabgaçlara bağlanan aileler arasında Chili 叱 利 sayılmakta ve bu ailenin adının sonraları $\mathrm{Li}$ 利 olarak değiştirildiğ kaydedilmektedir ${ }^{20}$. Aynı malumat Tong Zhi 通志'nın Shi Zu Lue 氏族略 bahsinde de mevcuttur ${ }^{21}$. Yine Tong Zhi'daki bir kayıtta Chili ailesi hakkında bazı tafsilatlar bulunmaktadır: "Bir rivayete göre Chilie 叱列 adlı kişi batı boylarının önde gelenlerindendi. Zamanla boyunun beyi olmuştu. Tabgaçlar Çin'e hâkim olup devlet kurunca bu beyin ailesine ve sülâlesine Chili 叱 利 adını vermişti. Sonraki Zhou devrinde (951-960) bu ailenin adı sadece Li 利 olmuştu ${ }^{22}$.

Zhou Sülâlesi devrinde (557-581) ad, Chifulie 叱 伏 列 şeklinde kaydedilmektedir. Yuan He Xing Zuan 元和姓 纂'1n bildirdiğine göre Zhou Shu 周 書'da kaydedilen Zhou Devleti'nde Büyük General ve Yongshi Gong (Bey)'u unvanlı Chifulie Chun 叱伏列 椿 $^{23}$ adlı kişi ve yine Changle Gong (Bey)'u Chifulie Gui 叱伏列龜 bu aileden gelmedir ${ }^{24}$.

Böylece ad, türlü kaynaklarda Chilie 叱列, Chili 叱利, Chifulie 叱伏列 gibi şekillerde görülmektedir.

Bu aile Qifu 乞伏 Xianbei 鮮卑'lerden gelmiştir. Qifuli 泣伏利 ailesi Tabgaç devrinde ise Qifu 乞 伏 adıyla görülmüsşür. Wei Shu'nun 86. cildinde yer alan Qifu Bao 乞 伏 保'nun biyografisinde onun Kaoche (Töles)' lardan gelme olduğu kaydedilmektedir. Buna göre Qifu Bao, Tabgaç İmparatoru Xian $\mathrm{Zu}$ devrinde (465-471) Tabgaç sarayında yüksek mevkilere gelmiş bir devlet adamıyd1 ${ }^{25}$. Çinli araştırmacı Chen Lianqinq'e göre bu kayıt bize Qifuli 泣 伏 ile Qifu 乞 伏’nun hemen hemen aynı olduğunu göstermektedir ${ }^{26}$. Qifu 乞伏 Xianbei 鮮卑’lerden gelme bir aile olması sebebiyle Töles ailesinin Xianbei menşeli olduğu neticesi ortaya çıkmaktadır. Nihayetinde Xianbei'ler ile Töleslerin müşterek ailelere sahip oldukları bilinmektedir. Xianbei Batı Qin 西秦 Devleti (385-431)'nin bânisi Qifu Guoren 乞伏國仁 (ölm. 388)'nın Jin Shu 晉書'daki biyografisinden bir rivâyet bu bakımdan hayli aydınlatıcıdır. Buna göre Qifu Guoren, Longxi'nin Xianbei'lerindendi. Eskiden Rufusi 如弗斯, Chulian 出連 ve Chilu 叱盧 adlı üç boy veya kabile vard. Bunlar Gobi Çölü'nün kuzeyinden güneye inip Ulu Yin Dağı'na gelmişlerdi. Yolda aniden kutsal bir kaplumbağa ile karşılaşınca hemen atlarını kesip ona kurban etmişler ve yollarının açılması için dualar okumuşlardı. Bunun üzerine hayvan gözden kaybolmuş ve küçük bir çocuk belirmişti. Bu esnada Qifu 乞 伏 adlı ailenin başının oğlu yoktu. Oğlanı evlat olarak almak istedi ve halk da bunu kabul etti. Bu çocuk daha sonra büyüyüp halkının başına geçti ve kagan oldu. İşte bu Qifu Guoren'ın beşinci kuşak atasıydı ${ }^{27}$. Bu rivayet bir menşe efsanesinden başka bir şey değildir. Okuduğumuz rivayet Xianbei'lerin ve

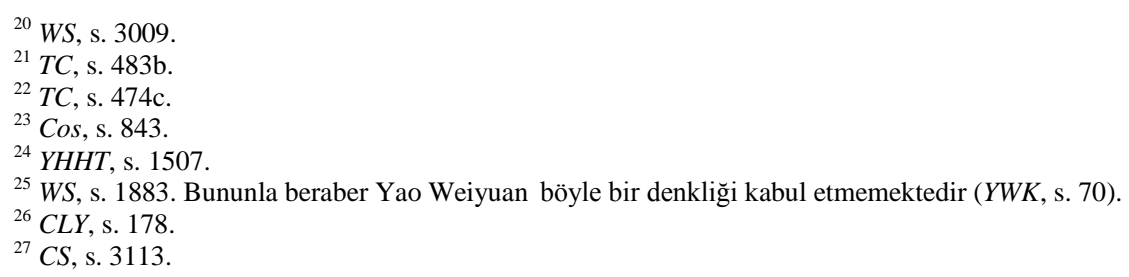


Tabgaçların müşterek menşe efsanelerindendir. Qifu ailesi M. S. 160-170 yıllarında güneye ilerleyen batı Xianbei'lerin terkibinde yer almaktadır ${ }^{28}$. Nihayetinde Xianbei ve Tabgaç boyları içerisinde birçok Töles ailesi bulunmaktadır ${ }^{29}$. Wei Shu ve Bei Shi gibi kaynaklarda Qifu 乞伏 ailesi, Qifu 乞佛, Qibu 乞步, Qifu 乞 扶 gibi şekillerde de geçmektedir ${ }^{30}$.

Yuan-Qiu da Qifuli ile Qifu ailelerini bir tutmaktadır ${ }^{31}$. Qifu ailesinin bazı dönemlerde birbirinden ayrılamayacak olan Xianbei ve Töles boylarının müşterek ailesi olarak kabul etmekte bir beis yoktur.

Adın formlarından biri olarak VI. yüzyılda geçen Chili 吨 利, Töleslere verilen adlardan biri olan Chile 敕 勒'ye çok benzemektedir. Bu hâliyle Töleslerin ilk ailesi olarak sayılan Chili aile adının Töles boy adının farklı bir okunuşu olması galip bir ihtimaldir.

Aile, Song (960-1279) devrinde yazılmış Çin aileleri listesi olan Bai Jia Xing 百家姓'da zikredilmektedir ${ }^{32}$.

Böylece bugün artık Çinlileşen ve yine Çin'in güneyindeki Lisu 傈 僳 halkı arasında görülen Li ailesi mensupları daha çok Henan taraflarında yaşamaktadırlar ${ }^{33}$.

\section{Jin 金:}

Yuan He Xing Zuan, Gujin Xingshi Shu Bianzheng 古今姓氏書辯證 ve Mingxian Shizu Yanxing Leigao 名賢氏族言行類稿'daki kayıtlara göre Jin 金 Ailesi, milâttan önceki yüzyılda Gansu'da hükmeden Hunların Xiutu 休 屠 Beyi’nden gelmedir. Beyin veliahdı Ridi 日磾 (M. Ö. 134-86), Çinlilere tâbi olmuş ve Çin İmparatoru Wu (M. Ö. 141-87)'ya üst düzey bir memur olarak hizmet etmiştir. İmparator, Xiutu Beyi'nin altın bir heykel yaptırıp göğe sunmasına göre Ridi'nin ailesine Jin 金 yâni "altın” adını bahşetmiştir. Ridi'nin kardeşi Lun ise Çin sarayında "Saray Kapısı Efendisi” (Huangmenlang 黃 門郎) olarak görev yapmıştır. Ondan doğan Anshan, “Şehir Yerleşimi Hürmetli Beyi” (Dutinggonghou 都停恭 侯) olmuştur. Bundan sonra bu Jin Ailesi'nin mensupları yedi kuşak Çin devleti içerisinde yüksek mevkilere gelmişlerdir. Çin'deki Tang İmparatorluğu'nun zhenguan saltanat devresinde (627-649), bu ailenin mensupları Gansu'da görülmektedir ${ }^{34}$.

Esasında Çin usulüne göre Jin aile adı alan Xiutu Beyi'nin oğlu Ridi'nin Çinlilere tâbi olmasıyla ilgili Han Shu 漢 書'daki Ridi'nin biyografisinde çok açık bir kayıt bulunmaktadır. Buna göre, Jin Ridi 金日磾, aslında Xiongnu (Hun) Xiutu Beyi'nin veliahdıdır. İmparator Wu'nun yuanshou saltanat devresinde (M. Ö. 122116), General Huo Qubing orduyu harekete geçirip Hunların sağ topraklarına hücum etmiş, çok sayıda kelle almış ve Xiutu Beyi'nin göğe sunduğu altın heykeli ele

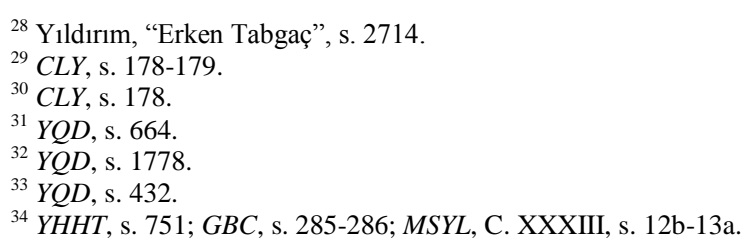


geçirmiştir. Bu harekâtın yazında Juyan'ı batıdan dolanıp Qilian Dağları'na saldırmış bu büyük zaferler elde etmiştir. Bundan sonra doğan vaziyet üzerine Hunya Beyi, Xiutu Beyi'ni öldürmüştür. Bunun üzerine Xiutu Beyi'nin halkı Çin'e sığınmıştır. Xiutu Beyi'nin oğlu Ridi ise anası ve kardeşiyle birlikte Çin sarayına gelmiştir. Bundan sonra Ridi Çin hizmetine girerek Çince Jin aile adını almıştır ${ }^{35}$.

$\mathrm{Bu}$ aile fertleri sonraları Tuge 屠 各 halkını teşkil etmiş ve bugünkü Gansu'daki Pingliang 平 凉 havalisinde yayılmıştır. Jin Shu 晉書 ve Wei Shu魏書 gibi kaynaklarda III. yüzyıldan sonra Çinlilerin çeşitli devirlerde hücum ettikleri Pingliang'daki Tuge halkının beyleri Jin Xi 金熙, Jin Bao 金豹, Jin An 金岸 gibi kişilerden bahsedilmektedir ${ }^{36}$ ki bunlar söz konusu Jin Ailesi'ne mensupturlar.

Muhtelif kaynaklarda Çin'e ilk tâbi olarak Jin aile adı alan ve M. Ö. 86 y1lında ölen Ridi'nin yedi kuşak neslinin Çin'e hizmet ettiği bildirilmiştir. Dolayısıyla muhtemelen Han İmparatorluğu'nun M. S. 220 yılında sona ermesiyle Çin devleti içerisindeki bu idareci aile Çin payitahtını terk edip ataları Hun Beyi Xiutu'nun toprağ 1 Gansu'ya dönmüşlerdir. Bu yüzdendir ki Han İmparatorluğu'ndan sonraki devirlerden bahseden Jin Shu ve Wei Shu'da bu ailenin yurdu Gansu'daki Pingliang olarak zikredilmektedir. Yine Gujin Xingshi Shu Bianzheng'da VII. yüzyıl havalisinde Gansu'da Jin ailesi mensuplarının zikredilmesi ${ }^{37}$ bu bakımdan gayet makuldür.

IV.-VI. yüzyıllarda Tibetli Qianglar arasında da görülen ${ }^{38}$ ve Song devrinin (960-1279) Çin aileleri listesi olan Bai Jia Xing 百家 姓’da 29. aile olarak yer alan $^{39}$ bu ailenin büyük oranda Çinlileştiği tahmin edilebilir. Yine de kesin bir hüküm vermek için daha fazla kaynağa ihtiyaç vardır, ancak hiç olmazsa Çin hizmetinde yedi kuşak duran, Çin devlet idaresinde ve orduda yüksek mevkilere gelen, muhtemelen Çin sarayından evlenen ve Çin usulü aile adı taşıyan aile mensuplarının Gansu’ya döndükleri esnada Çinlileştikleri düşünülebilir.

Chen Lianqing'in tespitlerine göre aile, Han İmparatorluğu emrindeyken payitaht Changan 長 安'daki Jingzhao 京兆'da yaşıyordu. Han devrinin sonlarına doğru ailenin beyi Jin Wei, imparatorluk içinde isyan eden Cao Cao (ölm. 220)'ya karşı hareket etmiş ancak öldürülmüştür ${ }^{40}$. Ailenin bundan sonra Çin merkezinden çıktığı öne sürülebilir.

Muhtelif kaynaklarda ailenin Longxi 龍西'deki mensuplarına Xiutu 休屠 $\mathrm{Hu}$ 胡'ları, Pingliang'dakilere Pingliang 平凉 Xiutu 休屠 veya Pingliang 平凉 $\mathrm{Hu}$ 胡'ları denilmiştir ${ }^{41}$.

Jin aile adını taşıyanlar bugünkü Çin Halk Cumhuriyeti’ndeki Beijing, Shanxi, Hebei, Shandong, İç Moğolistan, Yunnan, Sizhou gibi yerlerde yaşamaktadırlar. $\mathrm{Bu}$ ailelerin çoğu Çinlidir. Bununla beraber Mançu, Moğol,

\footnotetext{
${ }^{35} H S$, s. 2959-2961.

${ }^{36} Y W K$, s. 286-287.

${ }^{37} G B C$, s. 286.

${ }^{38}$ CWD, s. 210.

${ }^{39}$ YQD, s. 1778.

${ }^{40}$ CLY, s. 47.

${ }^{41}$ CLY, s. 47.
} 
Dungan, Koreli ve diğer sayıca az topluluklar arasında da görülmektedir ${ }^{42}$. Bu ailelerden bir kısmı Hunların neslinden gelip Çinlileşen Jin Ailesi mensuplarıdır.

\section{Yuwen 宇 文:}

Wei Shu, Zhou Shu, Gujin Xingshi Shu Bianzheng, Yuan He Xing Zuan, Xingshi Xunyuan 姓氏 尋 源 gibi kaynaklar bu ailenin Hunlardan geldiğini bildirmektedir. Wei Shu'daki Guan Shi Zhi 官氏 志 bölümünde kaydedildiğine göre Yuwen 宇 文 ailesi, Çin İmparatoru Xuan devrinde (M. Ö. 91-48) Hunların doğu yani merkez kısmında Murong 慕 容 ailesi ile beraber en güçlü iki aileden biriydi $^{43}$. M. S. 260-290 yılları arasında Yuwen 宇 文’ların beyi olan Mohuai 莫 槐'yın Wei Shu'daki biyografisinde ise, “Xiongnu (Hun) Yuwen Mohuai”yın Hunların Güney Chanyu'sundan geldiği ve kendisinin zamanla doğu kısmının beyi olduğu kaydedilmektedir ${ }^{44}$.

Kaynaklarda bu ailenin menşeine dair iki rivayet kaydedilmektedir. İlkine göre hür olan Hunlardan ayrılıp Çin'e tâbi olan Güney Hunlarının Chanyu'sünün torunu Gewuwen 葛烏莬, Xianbei 鮮 卑 Beyi oldu ve onun nesli beyliği devam ettirdi. Nihayetinde bu beylerden Puhui 普 回 av esnasında bir yeşimtaşı mühür ele geçirdi ve bunun Tanrı tarafından bahşedildiğini düşündü. Onların dilinde hükümdarların kullandıkları "göğün oğlu” (Çince karşılığı: Tianzi 天 子) ifadesi için “Yuwen 宇 文” sözü kullanılıyordu. Bu yüzden bey, ailesi için "Yuwen” adını aldı. Diğer rivayete göre mitolojik İmparator Shennong 神 農 (“Kutsal Çiftçi”), efsanevî Sarı İmparator 黃帝 tarafından öldürülünce onun evladı kaçıp kuzeydeki topraklara yerleşti. Xianbei 鮮卑 dilinde “çimen” veya “ot”a, “sifen 俟汾” deniliyordu. Shennong, çimen veya ot yediği için kendisine "Sifen 俟 汾” aile adı almış ve sonraları bu ad ses değişikliğine dönüşerek "Yuwen 宇 文” hâline gelmiştir" ${ }^{45}$. Bu iki rivayet biraz değişik şekilde Zhou Shu'daki Di Ji 帝紀 (“İmparatorluk Kayıtları”) bahsinin hemen başında yer almaktadır; burada farklı olarak, "yu: "gök", wen: "hükümdar" manasına gelir" şeklinde bir izah yapılmaktadır ${ }^{46}$.

Esasında ilk rivayetteki Güney Hunlarının Chanyu'sünün torunu Gewuwen 葛烏莬 ile ikinci rivayetteki kaçıp kuzeye yerleşen “imparator evladı”nın aynı kişi olması çok büyük bir ihtimaldir. Zaman ve şahıs unsurları muğlâk olmakla birlikte bir Hun kolunun "Çin" denen coğrafya içerisindeki varlığı ve mücadelede mağlup olup kuzeye kaçan mensuplarının Xianbei'leri teşkil etmesi veya en azından Xianbei'lerin idareci zümresi olması söz konusudur. Elbette ki milâttan binlerce yıl önce yaşadığına inanılan bir imparatora dair rivayetle milâdın başlarında Güney Hunlarına dair rivayetin birbirine benzemesinden hareket ederek hüküm vermek zordur ancak, çeşitli ana kaynaklardaki Yuwen ailesine dair malûmatlarda bu iki rivayetin bir arada sunulmasının bir sebebi olmalıdır.

\footnotetext{
${ }^{42}$ DOU, s. 299; YQD, s. 639-640.

${ }^{43}$ WS, s. 3012.

${ }^{44}$ WS, s. 2304.

${ }^{45} G B C$, s. 354; YHHT, s. 899; HSHY, s. 328.

${ }^{46} \operatorname{CoS}$, s. 1.
} 
$\mathrm{Bu}$ arada ikinci rivayet çok ilgi çekicidir. Nitekim Sifen 俟汾, Wei Shu'daki bir kayda göre V.-VI. yüzyıllarda Töleslerin on iki ailesinden biri olarak zikredilmektedir $^{47}$. Wei Shu'daki Töles aileleri kaydı dışında görülmeyen Sifen ailesinin adının Sifen 俟 汾 şeklinde de görüldüğü söylenmektedir ${ }^{48}$. Tong Zhi'daki Shi Zu Lue 氏 族略 kaydına göre kuzeye giden bir aile Xianbei olmuş ve Sifen ailesi olarak anılmaya başlanmıştır. Aile, Xianbei'lerin ailesi Yuwen 宇 文’ın ceddidir $^{49}$. Chen Yi, Yao Weiyuan gibi araştırmacılar Sifen adı ile Ruanruan (Juanjuan)'larda ve Gök-Türklerde görülen “erkin” unvanının karşılığı olarak Çin kaynaklarında geçen Sijin 俟 斤 sözü arasında bağ kurmaktadırlar ${ }^{50}$; eğer böyle bir bağ doğru kabul edilirse Sifen ailesinin adının “erkin” unvanının karşılığında eski Türk devletlerinde bir unvan olarak kullanıldığı düşünülebilir. Nihayetinde Çin mitolojisine ait ikinci rivayetin, tüm insanlığı Sarı İmparator'un nesli olarak gösteren Çin ananesi sebebiyle çok itibar edilebilir olmadığını söylemekte de fayda vardır. Bununla beraber bu mitolojik öğenin Türklerle ilgili bir varlığı aksettirdiği öne sürülebilir. Wei Shu'nun erken Tabgaç tarihinden haberler veren ilk cildindeki rivayete göre Çin'in kuzeyine yaşayan Tabgaçların atası Shijun'un, Çinlilerin mitolojik "Beş Aziz Hükümdar"'ndan üçüncüsü olan Ku'nun oğlu Yao'nun ${ }^{51}$ hizmetine girdiği kaydedilmektedir. Kahraman bir kişilik olarak sunulan Shijun, Etsin Göl (Ruo Irmağı)'ün kuzeyinde Çin mitolojisinde kuraklığa sebebiyet veren kötü ruh nüba'nın peşine düşmüştü. Elde ettiği başarılar sayesinde halkın kalbini kazanmış ve mitolojik "Beş Aziz Hükümdar"dan sonuncusu olan Hükümdar Shun'un teveccühüne mazhar olmuştu. Öyle ki Shijun Çin mitolojisinde "tarım tanrısı" olan tianzu ${ }^{52}$ mertebesine yükselmişti ${ }^{53}$. Bu mertebe esasında Çin tarihinde devlet kuran Türklerle ilgili bir bahis olarak görülebilir. Mesela büyük ölçüde Türk olduğu kabul edilen Çin'in ilk büyük ve gerçek devleti Zhou (M. Ö. 1046-256)'yu kuran kişi hakkında Çin klasiklerinde anlatılan öykü de esasen aynıdır ${ }^{54}$. Bu öyküde de devlet kuran "tahıl beyi" olan efsanevî bir kişi vardır, bu kişi yine Çinlilerin hizmetine girer, yükselir ve nihayetinde devletini kurar ${ }^{55}$. O hâlde Yuwen ailesine dair ilk rivayetin tarih zeminine oturtularak anlaşılması gerekir kanaatindeyiz.

\footnotetext{
${ }^{47}$ WS, s. 2310.

${ }^{48} C W Q$, s. 395.

${ }^{49}$ TC, s. $747 \mathrm{~b}$.

${ }^{50} C L Y$, s. 184

${ }^{51} \mathrm{SC}, \mathrm{s} .14$.

${ }^{52}$ Ci Yuan, Beijing, 2002, s. 2102.

${ }^{53}$ WS, s. 1.

54 "Shang Devleti zamanında Jiang kabilesinden Yuan Hanım, daha fazla çocuksuz kalmamak için kurban kesti. Daha sonra Gök Tanrı'nın ayak izine bastl ve hamile kaldı. Hou Ji yani "Tahil Beyi" ni doğurdu.Bebek dar bir geçide bırakıld, ancak koyun ve siğır onu sevgiyle korudular. Bebek uçsuz bucaksız ormana bırakılmıştı; ancak ormancılar onu korudu. Bebek donmuş buzun üzerine bırakıldı; ancak kuşlar onu kanatlarıyla korudular. Kuşlar ayrıldığında Hou Ji ağlamaya başladı. O anda annesi onun tabiatüstü bir varlık olduğunu anladl, onu sırtına ald ve büyüttü.Büyüyünce İmparator Yao'nun hizmetine girdi. Imparator onu At Ustasl (Seyis) yaptı. Hou Ji fasulye, hububat ve su kabağl ekti ve bereketlice yetiştirdi. Hou Ji, Shang Devleti'nin son şeytanî hükümdarını devirip Zhou Devleti'ni kurdu" (Christopher I. Beckwith, İpek Yolu Imparatorlukları, Çev. Kürşat Yıldırım, ODTÜ Yay., Ankara 2011, s. 2-3).

${ }^{55}$ Yildırım, "Erken Tabgaç", s. 2715.
} 
Milâdın başlarında geçen Hunlarla ilgili rivayete dönersek; Puhui'nin evladı Mona 莫 那, kuzeydeki Yin 陰 Dağı'ndan Liaoxi 遼 西'ye göçmüştür. Bu aile beylerinden bazılarının sonraları Hun hükümdarlarının Chanyu unvanını taşımışlardır $^{56}$. Güneye göç ile ilgili malûmatın Xianbei’lerin M. S. 160-170 yıllarındaki göçüne ${ }^{57}$ ait olduğu anlaşılmaktadır.

$\mathrm{Bu}$ aile mensupları Çin içerisinde kurulan birçok devlette yüksek mevkilere gelmişlerdir. Her şeyden önce Kuzey Wei Tabgaç Devleti (386-557)'nde Batı Bariyeri Büyük Valisi (Guanxi Da Dudu 關西大都督) ve daha sonra Kuzey Zhou Devleti (557-581) İmparatoru (ölm. 556) olan Yuwen Tai 宇文泰 zikredilmelidir. Sayılabilecek onlarca kişi arasında meselâ Kuzey Zhou Devleti (557-581)'nde Shenglie Generali (Shenglie Jiangjun 盛烈將軍) olan Yuwen Sheng 宇文盛; Sui Devleti (581-618)'nde general olan Yuwen Huaji 宇文化 及; Tang Devleti (618907)'nde Devlet Müfettişi (Lancha Yushi 藍察御史) olan Yuwen Rong 宇文融 gibi kimseler vardir ${ }^{58}$.

Batı Wei Devleti (535-557) ve Kuzey Zhou Devleti (557-581) devirlerinde Çin imparatorlarının Yuwen aile adını bazı kimselere mükâfat olarak bahşettikleri de bilinmektedir ${ }^{59}$.

Meşhur Çin aileleri listesi Bai Jia Xing 百家姓'da 434. aile olarak yer alan ${ }^{60}$ Yuwen ailesi tamamen Çinlileşmiştir. Bu aile mensuplarının çoğu bugünkü Shaanxi ve Shanxi'de yaşamaktadırlar ${ }^{61}$.

\section{Sonuç}

Türk milletine mensup bazı ailelerin Çin topraklarına yerleşip Çinlileştikleri tarihî bir hakikattir. $\mathrm{Bu}$ ailelerin nesli bugün de devam etmektedir. İçtimai tetkiklerde milletleri teşkil eden en küçük birim olan ailelerin adlarına ve tarihlerine müracaat edilebilir. Bu makalemizde Hun, Li, Jin ve Yuwen adlı Türk menşeli ailelerin kaynaklardaki ilk görünüşlerini, adların yazılışlarını ve okunuşlarını, adlardaki değişmeleri, ailelerin göçlerini ve bugünkü yayılma alanlarını ele almaya çalıştık. Çinlileşen Türk ailelerinin mensupları Çin'de kurulan devletler içerisinde yüksek mevkilere gelmiş ve Türk milletindeki idarecilik ve askerlik vasıflarıyla temayüz etmişlerdir. Ailelerin çeşitli sebeplerle Çin'in değişik bölgelerine yerleştikleri ve bazen de birbirinden çok uzak mesafelerde küçük topluluklar hâlinde dağıldıkları anlaşılmaktadır. Bazı tarih kayıtlarından bu ailelerin Türk toplumu içerisindeki yüksek mertebelerini ve itibarlarını Çin'de de muhafaza ettikleri görülmektedir. Maalesef bu aile mensupları bugün dilleri, âdetleri ve hatta etnik terkipleri bakımından Çinli olmuşlardır. Onlara Türk atalarından kalan yegâne miras ailelerinin adlarıdır. Belli kaidelere göre verilen veya alınan bu adların çok kadim devirlere kadar takibi esasen mümkündür. Böylece tarih, kültür ve etnoloji gibi araştırmalarda aile adlarına müracaat edilerek çok mühim neticeler elde etmek

\footnotetext{
${ }^{56} G B C, 354$.

${ }^{57}$ Yıldırım, "Erken Tabgaç", s. 2714.

${ }^{58}$ YHHT, s. 900-904; CWD, s. 524.

${ }^{59} Y W K$, s. 169.

${ }^{60} Y Q D$, s. 1778.

${ }^{61} Y Q D$, s. 361.
} 
mümkündür. Makalemizde bugünkü Çin Halk Cumhuriyeti'nde dağınık hâlde yaşayan Hun, Li, Jin ve Yuwen adlı ailelerin incelenmesine gayret edilmiştir.

\section{KAYNAKÇA VE KISALTMALAR}

BECKWITH, Christopher I., Ipek Yolu Imparatorlukları, Çev. Kürşat Yıldırım, ODTÜ Yay., Ankara 2011.

BS- Bei Shi, Zhonghua Shuju Chuban Yay., Beijing, 1997.

Chen Shaoxin-Furuide, Taiwan Renkou zhi Xingshi Fenbu, Taipei, 1970.

Ci Yuan, Beijing, 2002.

CLY- Chen Lianqing, Zhongguo Gudai Shaoshu Minzu Xingshi Yanjiu, Jilin Wenshi Chubanshe Yay., Changchun, 1993.

CoS- Zhou Shu, Zhonghua Shuju Chuban Yay., Beijing, 1997.

CS- Jin Shu, Zhonghua Shuju Chuban Yay., Beijing, 1997.

CWD- Chen Mingyuan-Wang Zonghu, Zhongguo Xingshi Cidian, Beijing Chubanshe Yay., Beijing, 1994.

CWQ- Chen Mingyuan-Wang Zonghu, Zhongguo Xingshi Daquan, Beijing Chubanshe Yay., Beijing, 1987.

DOU- Dou Xuetian, Zhonghua Gujin Xingshi Dacidian, Jingguan Jiaoyu Chubanshe Yay., Beijing, 1997.

EBERHARD, W., Çin’in Şimal Komşuları, Çev., N. Uluğtuğ, Türk Tarih Kurumu Yay., Ankara $1996^{2}$.

GBC- Gujin Xingshi Shu Bianzheng, Jianghsi Renmin Chubanshe Yay., Nanchang, 2006. XII. yüzyılda Teng Minshi tarafından kaleme alınmıştır.

HHS- Hou Han Shu, Zhonghua Shuju Chuban Yay., Beijing, 1997.

HLP- Xingshi Kaolue, Xue Hai Lei Bian, C. 100 içinde, Shanghai, Nüshası 1920. Bu kaynak Chen Tingwei tarafından 1831 yılında neşredilmiştir.

HOLMGREN, J., Annals of Tai Early T'o-pa History According to the First Chapter of the Wei-shu, Canberra 1982.

HUCKER, C. O., A Dictionary of Official Titles in Imperial China, California, 1985.

HSHY- Xingshi Xunyuan, Yuelu Shushe, Changsha, 1992. Aile ve sülâle adlar1 üzerine Zhang Shu (1776-1847) tarafından kaleme alınan bir kaynaktır.

JTS- Jiu Tang Shu, Zhonghua Shuju Chuban Yay., Beijing, 1997.

MAEDA Masana, Hexi Lishi Dili Yanjiu, Çin. Çev., Chen Junmo, Zhongguo Zangxue Chubanshe Yay., Beijing, 1993.

MSYL- Mingxian Shizu Yanxing Leigao. Zhang Ding tarafından 1209 yılında tamamlanan bir aile ve sülâle adları ansiklopedisidir. 1782'de tamamlanan Siku Quanshu Külliyatı içindedir; Zhechiang Üniversite Kütüphanesi nüshasından istifade edilmiştir.

ÖGEL, Bahaeddin, Büyük Hun İmparatorluğu Tarihi, C. I, Ankara, 1981.

SC-Shi Ji, Zhonghua Shuju Chuban Yay., Beijing, 1997.

SKC- San Guo Zhi, Zhonghua Shuju Chuban Yay., Beijing, 1997.

SS- Sui Shu, Zhonghua Shuju Chuban Yay., Beijing, 1997.

Studia Asiatica, The Collected Papers in Western Languages of the Late Dr. Kazuo Enoki, ed. R. Kono, Tokyo, 1998.

SuS- Song Shi, Zhonghua Shuju Chuban Yay., Beijing, 1997.

TAŞAĞIL, Ahmet, Çin Kaynaklarına Göre Eski Türk Boyları, Ankara, 2004. 
TC- Tong Zhi, Shangwu Yay., Shanghai, 1935.

WANG Quangen, Zhongguo Xingshi de Wenhua Jiexi, Tuanjie Chubanshe Yay., Beijing, 2000.

WS- Wei Shu, Zhonghua Shuju Chuban Yay., Beijing, 1997.

WXTP- Wang Xing Tong Pu, Chengdu, 1995. Ling Dizhi tarafından XVI. yüzyılın sonlarında tamamlanan kişi ve aile adları ansiklopedisidir. Bashu Shuhe Yayınevi'nin nüshasına müracaat edilmiştir.

XTS- Xin Tang Shu, Zhonghua Shuju Chuban Yay., Beijing, 1997.

YHHT- Yuan He Xing Zuan, Zhonghua Shuju Chuban Yay., Beijing, 1994. Tang İmparatoru Xian Zong'un emriyle Lin Bao tarafından yazımına başlanan ve 812 yılında tamamlanan bir tür aile adları ansiklopedisidir. Kaynakta 1232 ad vardır. Kaynağın Cen Zhongmian tarafından yapılan tahkikli nüshasından istifade edilmiştir.

YILDIRIM, Kürşat, “Erken Tabgaç (T'o-pa) Tarihinin Ana Hatları (Wei Shu'nun İlk Bölümüne Göre)", Turkish Studies, VII/3, 2012. , Çin Kaynaklarında Türkistan Şehirleri, İstanbul, 2013.

YQD- Yuan Yida-Qiu Jiaru, Zhongguo Xingshi Dacidian, Jiangxi Renmin Chubanshe Yay., Nanchang, 2010.

YWK- Yao Weiyuan, Beichao Huxing Kao, Zhonghua Shuju Chuban Yay., Beijing, 2007.

Zhongguo Lishi Diming Da Cidian, Ed., Shi Weile, Beijing, 2005. 